\title{
Teología Fundamental Práctica. Una propuesta a partir de Johann Baptist Metz ${ }^{1}$
}

\author{
Practical fundamental theology. A proposal \\ from Johann Baptist Metz
}

Edwin Raúl Vanegas Cuervo. Pbro. ${ }^{2}$

\begin{abstract}
Resumen
El teólogo alemán Johan Baptist Metz dirige su reflexión hacia el carácter práctico de la teología y la vida cristiana. En el camino de su propuesta nos plantea la valoración de las categorías fundamentales de esta nueva teología: recuerdo, narración y praxis. Estas categorías irán perfilando las nuevas condiciones del discurso sobre Dios y las actitudes del teólogo que quiera enfrentar su reflexión a las apremiantes condiciones de la sociedad secularizada y a la privatización de la experiencia cristiana. No se puede entender la teología encerrada en sí misma y sin capacidad de auto crítica, ya que dentro de su estructura más profunda no es privada sino pública. El recuerdo peligroso de la pasión y muerte de Jesús es el centro de esta nueva teología fundamental práctica y debe encontrar en la narración y la praxis de la solidaridad universal los medios para incidir en el escenario de la historia contemporánea. Para esta tarea el teólogo se esfuerza por agudizar sus actitudes de crítica, diálogo y praxis.
\end{abstract}

Palabras clave: Teología fundamental; Recuerdo; Narración; Praxis; Secularización. Solidaridad.

\begin{abstract}
The German theologian Johan Baptist Metz directs his reflection towards the practical character of theology and Christian life. In the way of his proposal, Metz sets out the valuation of the fundamental categories of this new theology: memory, narration and praxis. These categories will outline the new conditions of the discourse on God and the attitudes of the theologian who wants to face his own reflection to the pressing conditions of the secularized society and to the privatization of the Christian experience. It is not possible to understand theology enclosed within it self or without selfcriticism capacity, since within its deepest structure is not private but public. The dangerous memory of the suffering and death of Christ is the center of this new practical fundamental theology, and it must find in the narration and praxis of universal solidarity the means to influence the stage of the contemporary history. For achieving this task, the theologian strains for sharpening his attitudes of criticism, dialogue and praxis.
\end{abstract}

Keywords: Fundamental theology; Memory; Narration; Praxis; Secularization. Solidarity.

Artículo de Reflexión.

2 Teólogo de la Pontificia Universidad Gregoriana. Docente Unimonserrate. E-mail: pedwinvanegas@arquibogota.org.co 


\section{Introducción}

El teólogo alemán Johann Baptist Metz es considerado precursor de la nueva teología política y la persona que, en sus más de 45 años de reflexión, ha aportado al avance de la teología fundamental. Su reflexión y producción teológica son pertinentes en las condiciones de una sociedad contemporánea que pide dar razones de la esperanza y la vida cristiana. Metz en el desarrollo de su teología trata temas fundamentales que parecen insondables en la tradición teológica o en algunos casos, temas que se han evitado. Entre esos cuestionamientos, se encuentra la permanente inquietud por la praxis de la vida cristiana. Metz ha evidenciado el fenómeno de privatización de la experiencia y discurso cristiano, que le ha conducido a perder la capacidad de crítica y auto crítica. Por tanto, el teólogo contemporáneo tiene como misión colocar la reflexión de la fe y la vida cristiana en el terreno de lo público, para que de esta manera, se pueda dar la irrupción del mensaje de Cristo y éste pueda incidir en la construcción de una nueva sociedad.

El presente artículo, apoyado en la propuesta de Metz, se convierte en un ejercicio de reflexión teológica aplicable a las nuevas condiciones que debe enfrentar el teólogo fundamental en su vocación teológica. Para el teólogo es urgente la tarea de ofrecer un camino reflexivo y crítico ante peligros de la privatización y la secularización. De la mano del teólogo alemán iremos precisando el ser y quehacer de la teología fundamental y, además, la necesaria conversión en las actitudes del teólogo.

Es oportuno precisar que en este escrito se centra en la obra más importante de Metz, que se puede entender como la columna vertebral de todo su esfuerzo teológico. Esta obra es La fe, en la historia y la sociedad escrita en 1977 y que tiene como subtítulo: Esbozo de una teología fundamental para nuestro tiempo. A partir de la lectura crítica de esta obra se propone rescatar los principales elementos de la nueva teología fundamental y las categorías que deben ser apropiadas por el teólogo para alcanzar los fundamentos y la praxis de la vida cristiana en las actuales circunstancias de nuestra cultura posmoderna.

El itinerario que seguiremos por medio de este texto es el siguiente: Exponer en primer lugar qué debe entenderse por teología fundamental práctica; seguidamente las categorías que sostienen esta teología; y concluir con una reflexión personal sobre las actitudes del teólogo para nuestro tiempo.

\section{Teología política, como teología fundamental práctica}

A través del análisis de la Ilustración y sus consecuencias, la teología fundamental encuentra su objeto, método y tareas específicas dando respuesta a la crisis de la teología sufrida por la incursión de las ideas de la Ilustración en todas las dimensiones del saber y el obrar humano. Siguiendo a J. B. Metz presentamos la situación actual de la teología fundamental como disciplina teológica que tiene que ver con la reflexión crítica y práctica de la experiencia cristiana.

\subsection{La Ilustración y el carácter apologético práctico de la teología fundamental.}

Como punto de partida en el desarrollo de la teología fundamental actual está la citación bíblica tomada de la primera carta del apóstol Pedro: Dad culto al Señor, Cristo, en vuestros corazones, siempre dispuestos a dar respuesta a todo el que os pida razón de vuestra esperanza (1Pe. 3; 15). Tomando esta cita bíblica J.B. Metz afirma tajantemente cuál debe ser el objetivo del quehacer teológico, en medio de la situación de ilegitimidad de la metafísica y la teología, ocasionada por el desarrollo global y acelerado de la Ilustración del siglo XVIII y XIX. Metz (1979) hace un llamado a la teología como 
apología de una esperanza (p.2), que sea respuesta a la crisis ocasionada por la racionalidad, el progreso y el materialismo en el cual se encuentra el mundo.

La corriente iluminista ha logrado desencadenar en el ser humano una nueva comprensión del mundo y una nueva forma de expresión, haciendo que exista un lenguaje universal cuyas palabras fundamentales son evolución y progreso. Estos términos expresan un nuevo espíritu con el que el ser humano piensa y vive. La teología no puede hacer caso omiso a esta nueva situación, tampoco puede seguir encerrada en un discurso privativo, ni mucho menos dejarse diluir en un cristianismo a-histórico o secularizado. La teología fundamental entra en este escenario como una apologética de la esperanza, que, a diferencia de la apologética clásica, no solo es una respuesta teórica o de demostración, sino que tiene que ver con una crítica de la historia y que conduce a una praxis cristiana transformadora. Metz expresa el carácter apologético de la teología fundamental, diciendo: "Una teología fundamental que se entienda como investigación de los fundamentos de la teología tiene por fuerza carácter apologético, y no solo incidentalmente o como vestigio histórico sino esencialmente" (Metz, 1979, p.22).

La necesidad de una teología fundamental práctica para nuestro tiempo nace como consecuencia del análisis de la situación grave y significativa, debida a dos grandes cambios producidos por la Ilustración y que han afectado de manera directa al cristianismo y la teología: ya no se puede identificar la fe cristiana con la conciencia religiosa; se ha roto la unidad entre religión y sociedad, entre vida religiosa y vida social.

\subsection{Respuestas a la crisis teológica originada por la Ilustración}

La Ilustración genera al interior de la teología una crisis que da como origen el despertar de una nueva apología. Metz agrupa en tres tendencias, lo que ha llamado e1 frente apologético, que en la escuela alemana encuentra su más destacado desarrollo. Sin embargo, estas tendencias teológicas son insuficientes o limitadas en la solución de un problema que sobrepasa el ámbito de la razón hacia uno más complejo que es el de la praxis.

\section{a. La neoescolástica}

Esta apologética se puede ubicar entre la segunda mitad del siglo XIX hasta la década de los años 30 del siglo XX. El contexto está enmarcado por las grandes críticas ideológicas a la religión comandadas sobre todo por personajes como Feuerbach, Marx y Nietzsche. Ante este desafío la nueva apologética busca regresar a los fundamentos de la filosofía moderna y la ciencia, para desde allí proponer una justificación a la altura de la racionalidad gobernante. "La neoescolástica busca una base segura en el pasado, recurriendo directamente a las tradiciones modernas. Esta teología encuentra su expresión clásica y de forma reveladora en la obra Teología del Pasado de Kleutgen" (Metz, 1979, p.31).

\section{b. La doctrina social de la Iglesia}

Ante el constatable rompimiento de la relación entre religión y estado, que ha traído consigo la Ilustración, la Iglesia siente una pérdida en el carácter normativo y universal del cristianismo dentro del conjunto del comportamiento y acción social en el mundo. Para atender a esta carencia se incrementa la reflexión y producción de textos magisteriales que quieren presentar y actualizar la posición de la doctrina católica en los problemas sociales y políticos del siglo XX.

La doctrina social de la Iglesia constituye un descargo frente al reto político del tiempo. Se trata, de un intento, indirecto, de salvar los problemas y cuestionamientos fundamentales de 
la fe y de la teología al margen de los cuestionamientos de la época. (Metz, 1979, p.33)

\section{c. El tradicionalismo}

Se desarrolla como contraposición crítica, casi siempre negativa, frente a la versión político-revolucionaria de la Ilustración. Esta respuesta teológica ha sido liderada de manera particular por los laicos franceses a principios del siglo XIX, animados por el impacto de la Revolución Francesa y el auge de la Modernidad fundada sobre la razón. Las principales críticas de los tradicionalistas se manejan en el ámbito de un rechazo al dominio de la razón, sobre todo en la dimensión de la legitimidad de la autoridad y la proclamación de la autonomía del hombre vociferado por la Revolución Francesa.

El menosprecio tradicionalista de la razón no forma parte primariamente de un complejo de intereses teológicos, sino que sirve casi exclusivamente al interés de restaurar la concepción monárquica de la soberanía frente a la idea de la democracia burguesa, que apelaba por su parte a una autonomía de todos los individuos basada en la razón humana. (Metz, 1979, p.35)

\subsection{Origen de la nueva apologética como teología fundamental}

Las tendencias teológicas de respuesta frente a la dura crítica que ha generado la Ilustración para la religión cristiana, se han dado de manera alterna con diferencias en el objetivo o acentos de cada una, encontrándose mutuamente en el intento apologético y la apropiación del nuevo lenguaje ilustrado que el mundo ha tomado. Sin embargo, la respuesta a la crisis era insatisfactoria y agudizaba el rompimiento de la relación entre la teología dogmática y la teología fundamental. Se crean las condiciones para el surgimiento de una nueva teología que logre relacionar los diversos frentes apo- logéticos y trate de defender la fe cristiana en un diálogo con las tradiciones modernas.

El espíritu que mueve el anhelo de una nueva apologética logra vencer la tendencia de aislamiento de la neoescolástica frente a las tradiciones filosóficas y científicas de la Edad Moderna. Se entabla un diálogo con las tradiciones modernas no solo de manera defensiva, sino con la voluntad de asimilación crítica y fecunda, que permita no solo el crecimiento de la apologética, sino también de la teología sistemática. Abanderados de este intento se encuentran en la Escuela de Tubinga.

La apologética se va convirtiendo en teología fundamental cuando en su desarrollo y en la consecución de su método tiene en cuenta los problemas fundamentales de la fe y no un obstinado espíritu defensivo o evasivo ante las corrientes modernas que ha generado la Ilustración. Vale la pena llamar la atención a la manera como la escuela francesa pudo realizar, en consonancia con el aporte de la filosofía de Maurice Blondel, la llamada apologética de la inmanencia, que colocó la teología en diálogo y confrontación sería con las ideas del modernismo francés. Sin embargo, es en la obra de Karl Rahner donde se puede ver el alcance del desarrollo de la nueva teología del siglo XX, recuperando la tradición apologética y teológico-fundamental en el foro interno de la teología, por medio de la distinción entre teología "formal" y teología "material". Esta distinción es explicada por Metz:

En la teología fundamental deben estudiarse las estructuras formales de la fe dogmática; la teología fundamental es en cierto modo dogmática formal y, a la inversa, la dogmática sólo tiene sentido si se convierte en teología fundamental material, es decir, si expone sus contenidos dogmáticos articulándolos con los problemas del tiempo: "Oyente de la palabra» en sentido teológico solo puede serlo quien a un mismo 
tiempo escucha las objeciones de su tiempo y comparte los problemas de su entorno" (Metz, 1979, p. 37).

El panorama para el desarrollo de la nueva teología fundamental encuentra un desafío grande y surgen las problemáticas relevantes de la relación de la teología con el mundo, la historia y el progreso. La inquietud por el imparable proceso de secularización hace ver que la crisis de la Ilustración no ha sido superada del todo, sino que ha producido nuevos planteamientos. (Vale la pena recordar que a través del desarrollo de su obra Teología del Mundo, (Metz, 1970, pp.73-103) intenta responder a esta crisis no superada por la teología moderna y un ejemplo de esto es la afirmación fundamental que hace el autor donde el misterio de la encarnación es el principio de la secularización).

El primero de ellos tiene que ver con el sujeto de la teología y el otro planteamiento se refiere a la praxis del cristianismo en medio de un mundo secularizado, emancipado e ilustrado.

Hemos llegado al punto central desde dónde se plantea la necesidad de hacer una teología política como teología fundamental práctica, cuyo objetivo ha de ser: devolver al concepto de praxis su radicalidad cristiana y lo haga aplicable también al sujeto no burgués, aquello que (Metz, 1979, p. 40) entiende por sujeto burgués está expresado claramente con sus mismas palabras:

Lo que en la Ilustración se realiza y luego en el curso de la época moderna se afirma y se absolutiza es el surgimiento de un hombre nuevo, el burgués; el sujeto burgués se establece en la teología moderna gracias al liberal abrazo de ésta con la Ilustración; que finalmente, y sobre todo, un determinado concepto burgués de praxis ha reprimido el concepto genuinamente cristiano de praxis y libertad socio-crítica, es decir, lo ha reducido a la esfera privada del sujeto que vive sin problemas en la sociedad y a su honestidad normal.

De tal forma, que todos los hombres sin excepción puedan hacerse sujetos de la teología y ser protagonistas de la praxis liberadora que trae la memoria peligrosa de la pasión y resurrección de Jesucristo.

La aparición del sujeto burgués y la distorsión o pérdida de la categoría de praxis del cristianismo son los nuevos lugares desde los cuales la teología fundamental debe reflexionar y colocar de nuevo a todo ser humano, como protagonista, en la dinámica de una religión cristiana que lo conduzca hacia la realización del Reino definitivo y escatológico, en el cual va tomando forma una comunidad más justa y libre de toda privatización del discurso y la praxis de la religión. La teología práctica, desde la perspectiva de Metz, nos aporta tres categorías fundamentales que nos disponemos a presentar.

\section{Categorías de la teología política como teología fundamental práctica}

Hablar de categorías de la nueva teología política, debe entenderse como el conjunto amplio donde se sistematizan las condiciones existenciales de la experiencia cristiana, para que sean totalmente prácticas. Detrás de cada categoría hay una sistematización de otras realidades que inciden en el sujeto teológico y la realidad histórica y social que lo circundan. Las categorías influyen de manera axiológica y amplían los temas y conceptos propios de la teología política como teología fundamental práctica. Estas categorías son: memoriarecuerdo, narración y solidaridad.

\subsection{Memoria-Recuerdo}

El recuerdo y la memoria son categorías esencia- 
les para la mentalidad judía y helenista, las cuales influyen de manera decisiva en el desarrollo histórico del cristianismo. El recuerdo ha alcanzado un rango singular en el ámbito teológico porque posee unas características que han hecho de esta categoría un punto central y único en la permanencia a través del tiempo y la historia, del mensaje y obra de Jesucristo. Al referirnos al recuerdo en la teología cristiana, se ha querido expresar en primer lugar "la relación de mediación entre la razón y la historia; en segundo lugar, la categoría de recuerdo en cuanto resumen de los caracteres básicos tanto de la filosofía como del pensamiento tradicional judeo-cristiano" (Metz, 1979, p. 193).

Cuando se habla del recuerdo en un ámbito pragmático y utilitarista se corre el riesgo de referirse a una realidad lejana, acabada, abandonada, sin incidencias en el presente. Por tal razón, es necesario redescubrir el significado teológico del recuerdo, para legitimar las realidades conexas a esta categoría, tales como: tradición, apocalíptica, memorial, escatología, etc. El desarrollo del recuerdo como categoría es perceptible por medio de cuatro características que le son propias:

1. El recuerdo posee una fuerza solidaria con el pasado y una apertura a la esperanza escatológica. No es una simple remembranza del pasado, sino es un recuerdo peligroso, en el sentido que hace presente la memoria de los muertos y vencidos, colocando a la teología en solidaridad con las víctimas.

2. Tiene la capacidad de ser trasmitido a través de los distintos modos de vida social dentro de la Iglesia. En esta característica se sostiene la importancia de la Tradición y la Iglesia como comunicadora o transmisora oficial de la memoria peligrosa de Jesucristo en el mundo y en la historia. La Iglesia por medio de la memoria reconoce permanentemente que la fe y sus expresiones sociales son dinámicas y no permanecen estáticas en el tiempo, sino que son actualizadas a través del cumplimiento de su misión en el mundo.

3. Su función es interpretar de manera crítica la historia y la sociedad. La nueva interpretación se da desde el clamor de los vencidos y no de los vencedores. El recuerdo del que debe hacer uso la teología política debe propiciar la crítica ante cualquier forma de reducción del tiempo y la historia.

4. Facilita la conciencia apocalíptica dentro de la teología. Ante toda reducción inmanentista o evolucionista de la historia, donde el hombre se ve sumergido en un profundo presente estático o un futuro oculto y trágico, el recuerdo como categoría teológica evoca e incita en la persona y la sociedad el dinamismo y el poder transformador de la historia, a partir de un concepto del tiempo desde la perspectiva de la esperanza cristiana y la praxis del seguimiento.

Unido a las anteriores características, el recuerdo se presenta en la teología política como un medio de realización práctico de la razón en cuanto libertad, como una estructura narrativa y en relación con las tradiciones de la anamnesis y la memoria cristiana. La libertad es un elemento esencial en el desarrollo de la historia y de la razón del sujeto. El tipo de recuerdo propio de la razón crítica es el recuerdo de la libertad (Metz, 1979, p. 204), de él nace el interés que motiva y rige la realización práctica de la razón.

Quiero detener mi atención al aspecto de anamnesis y memoria peligrosa que tiene el cristianismo, como elementos constitutivos de la categoría de recuerdo en el planteamiento de la teología política. Para referirnos a la anamnesis y la memoria, debemos tener en cuenta un problema social y cultural de nuestro tiempo como es la amnesia cultural, que define Metz (2002) en su obra Dios y Tiempo, de la siguiente manera: 
Cuando hablamos de amnesia cultural nos referimos al silenciamiento del dolor del recuerdo en la memoria cultural del hombre. Jean François Lyotard ha resaltado con acierto que en realidad hay dos clases de olvido: por un lado, borrar todas las huellas para que no sea posible volver a recordar; $y$, por otro lado, y en contraposición al anterior, el recuerdo «perfecto», es decir, la disposición de que, en y por la representación de los sucedido, queda asumido y aclarado lo que acaeció. (p.171)

El olvido es una condición que ha marcado el desenvolvimiento de la historia, de la sociedad y, de manera directa, se opone a la tradición cristiana que se basa en el recuerdo de la memoria peligrosa del misterio pascual de Cristo. La memoria passionis, mortis et resurrectionis Jesus Christi es aquella clase de recuerdo peligroso que se actualiza en la vida de la Iglesia. Se trata de:

una memoria peligrosa y liberadora, que en el día de hoy nos está siempre acuciando, porque el recuerdo no es de un futuro cualquiera, sino del que se describe en la vida de Jesús, en su testamento, que nos obliga a estar cambiando constantemente para poder responder a sus exigencias. (Metz, 2002, p. 76)

La teología política por medio de la categoría del recuerdo conducirá al teólogo y al cristiano a colaborar en la construcción de una nueva cultura que rechaza la amnesia y el olvido y boga por la consolidación de una cultura anamnética, que no sólo surja de la dimensión religiosa, sino que evoque e impregne las dimensiones comunicativas y simbólicas de la sociedad. Una cultura anamnética será el futuro de la teología como mística y espiritualidad, que reconoce el carácter universalista que nace del recuerdo del sufrimiento.

\subsection{Narración}

Desde un análisis fenomenológico se percibe que en el mundo y el hombre existe una experiencia de la narración y que de forma especial el cristianismo posee dicha estructura. Por medio de la narración la teología ha podido responder la crítica sobre el carácter no objetivo e inexpresable de la tradición cristiana en sus contenidos y formas prácticas. Es una tarea urgente de la teología devolver al aspecto narrativo de la fe su lugar como camino e instrumento de comunicación de la experiencia creyente originaria: el memorial de Jesucristo muerto y resucitado.

Se puede afirmar que la tradición bíblica es el primer testimonio donde podemos constatar que existe una estructura narrativa en la experiencia de la fe del pueblo de Israel y del Cristianismo. Un punto de unión entre la experiencia de la fe del pueblo elegido y la comunidad cristiana está en el continuo cambio de un estado antiguo a uno nuevo que se trasmite en las narraciones originales y originarias. La novedad trasmitida consiste en la destrucción por parte de Dios de todo aquello que se opone a la incomparable novedad del Cristo resucitado, dador de vida y futuro escatológico realizable.

Para poder aprovechar la categoría de narración, la teología debe prevenir el peligro de reducir esta categoría al espacio de los relatos o mega relatos, carentes de profundidad y significado, lejanos de las experiencias objetivas y sin precedentes que se han mantenido en la conciencia creyente por muchas generaciones. Este objetivo se logra precisando tres dimensiones que son propias de la narración en el desarrollo de la teología política que deben estar siempre presentes: el sentido práctico, el sentido pastoral y el sentido teológico de la categoría de la narración. a. Sentido práctico 
Las narraciones siempre ponen en evidencia realidades diversas pero necesarias, que interactúan y hacen posible el desarrollo de las estructuras narrativas y lingüísticas. "La narración tiende a la comunicación práctica de la experiencia en ella acumulada y evidencia cómo el narrador y los oyentes se incorporan -liberándose- a la experiencia relatada" (Metz, 1979, p. 215). La narración siempre tiene que ver con las experiencias vitales, que han llegado a un significado trascendental en el individuo, pero que al ser expresadas por medio del narrador, se convierten en experiencias comunitarias.

La narración y el proceso por el cual se expresa, son siempre portadores de una experiencia que involucra y libera; en algunos contextos alcanza incluso un valor sagrado y ético. La fidelidad a la narración por parte del narrador y la disposición de los oyentes son condiciones necesarias para que la narración alcance su objetivo, que consiste en ser trasmisora de significado y liberación para quienes no son escuchados o para quienes no pueden expresarse.

Dentro del cristianismo la estructura narrativa alcanza un momento importantísimo, sobre todo en las acciones sacramentales, especialmente la Eucaristía, que es el momento en el cual, la memoria de la muerte y resurrección de Jesucristo se hace explícita por medio de la narración. No es un relato de un pasado acaecido, sino que la narración de la cena de Jesús y sus discípulos posee un carácter liberador eterno. En las realidades sacramentales la realidad verbal y la realidad fáctica alcanzan una unidad esencial por medio de la narración.

\section{b. Sentido pastoral}

Metz (1979) describe con preocupación, pero también con una valoración positiva, el florecimiento de las experiencias religiosas que dan prioridad a la fuerza de la narración del testimonio de vida, como elemento fundamental dentro de la práctica y sostenimiento del culto. Lo preocupante es que muchos de estos grupos se consideran sectarios o incluso marginales dentro de la misma Iglesia.

Por lo general los grupos y "movimientos marginales" no suelen argumentar. Más bien narran, o mejor dicho, intentan narrar. Narran la historia de su conversión o vuelven a contar las historias bíblicas, con frecuencia de un modo descuidado, muy fácil de comprender y manipular. (p.218)

Esta situación deja, positivamente, un campo abierto para el desarrollo de una pastoral que parte del anuncio kerigmático, donde la pastoral y la predicación se encuentren y alcancen la unidad por medio de la narración del acontecimiento peligroso y salvador de la muerte y resurrección de Jesucristo. La crisis de la pastoral de hoy es generada por la ausencia del anuncio kerigmático y se constata en que la fuerza transformadora del mensaje escatológico parece no tener incidencia en la realidad del mundo secularizado. Ante esta crisis, se puede responder con una profundización de la estructura narrativa como camino pastoral.

Existe hace mucho tiempo una crisis narrativa en el cristianismo no solo en el ámbito de la fe vivida, sino en el quehacer teológico. La teología política teniendo en cuenta esta crisis pastoral aboga por el rescate de la narración como categoría de trasmisión de la memoria Christi, de tal forma que alcance a todos los hombres, para que puedan escuchar el recuerdo peligroso que libera y comprometerse con la construcción del reino definitivo, donde serán llamados, de manera especial, los sufrientes y las víctimas. Ante esta crisis la Iglesia deberá prepararse para redescubrir su papel como narradora de las historias de aquellos que no han podido expresarse 
porque el mundo les ha cerrado las posibilidades materiales y espirituales.

\section{c. Sentido teológico}

La narración permite alcanzar la unión entre la razón y la historia. La narración opera como mediadora entre la salvación y la historia. La narración tiene una función mediadora en sentido teológico permitiendo la reconciliación entre la vida histórica como experiencia de no identidad y la salvación como narración de la memoria de Jesucristo.

El cristianismo como comunidad de los que creen en Jesucristo es fundamentalmente una comunidad del recuerdo y la narración que posee en su esencia una estructura que la hace práctica. Cuando la fe no valora adecuadamente esta realidad salvífico narrativa y reduce la memoria de Jesucristo a una dimensión solamente mitológica, inmediatamente cancela la incidencia histórica del acontecimiento único e insoslayable de la muerte y resurrección del Señor. Es en el carácter memorial y narrativo que tiene el misterio pascual, donde encontramos la responsabilidad del cristianismo con la salvación del mundo y la historia que se presentan con el rostro del sufrimiento, la fragmentación y el sin sentido. "La teología que pueda cumplir este papel de mediación entre la salvación y la historia del sufrimiento, debe ser una teología 'rememorativa' y 'narrativa' ' (Metz, 1973, p. 233).

\subsection{Solidaridad}

Los procesos de Ilustración y secularización, han portado como consecuencia el olvido del sujeto, sobre todo, el olvido del ser humano que sufre y está asilado por la mano, falsamente salvadora, de la modernidad y el progreso. La historia acentúa una fuerte orientación hacia el costado de los vencedores, como abanderados de la mayoría de edad que piensan haber alcanzado el grado más alto de humanidad. Esta condición actual, unida al análisis que hemos hecho hasta el momento, nos introduce en una de las categorías más urgentes de la nueva teología fundamental: la solidaridad. Esta categoría esencial se convierte en la finalidad concreta de todo discurso crítico de la teología y la praxis cristiana. "La solidaridad como categoría de una teología fundamental práctica significa asistencia, apoyo y promoción del sujeto frente a sus graves amenazas y sufrimientos" (Metz, 1979, p. 237).

La sociedad moderna habla de unos canjes de la solidaridad, mediados por el interés puesto en el progreso, marca como punto de inicio un intercambio entre iguales, dejando de lado a quienes marcan diferencia en la sociedad, a las víctimas, a los sufrientes, aquellos que no han alcanzado la mayoría de edad, como objetivo de la Ilustración.

La solidaridad es cualitativamente algo más que un pacto finalista entre partes iguales $y$, desde luego, el humanismo, algo más que un humanismo de objetivos, esto es, un compromiso sin cálculos previos con la vida oprimida: esta idea cristiana brilla cada vez más por su ausencia. (Metz, 1979, p. 239)

La solidaridad se presenta como categoría de salvación del sujeto donde quiera que se encuentre amenazado por la opresión, por la muerte, por el olvido, por el aislamiento. La solidaridad es el compromiso universal de la humanidad que favorece el protagonismo de cada individuo frente a su propia salvación y la participación de la redención realizada por Cristo, de manera universal y definitiva. La perspectiva creyente de la solidaridad nos ofrece la comprensión del sujeto y el alcance de una verdadera acción solidaria.

\section{a. Sujetos de la solidaridad}

La solidaridad está apoyada en la valiosa realidad humana de la comunicación. El intercambio vital entre los humanos define una lógica de necesidad 
y dependencia intersubjetiva. El lenguaje y los signos, como convenciones universales, reflejan claramente esta realidad fundamental de la humanidad. En la experiencia vital del ser humano se da una dinámica de intercambio permanente, no solo material, también a niveles profundos y existenciales, que van definiendo su lugar dentro de la historia y la transformación de la naturaleza. Frente a esta solidaridad recíproca el cristianismo resalta por medio de la solidaridad acompañada de la memoria y la narración. En la afirmación de las relaciones interpersonales como mediadoras de una solidaridad cristiana, hay un descubrimiento de la verdadera correspondencia entre un yo y un tú, en la dimensión del encuentro del rostro sufriente, que interpela y anima la decisión libre y comprometida de la praxis cristiana. En este punto Metz se ha dejado inquietar por el pensamiento de Emmanuel Lévinas y así lo ha expresado:

Me ha causado impacto el comprobar hasta qué punto sabe ver él [Lévinas] lo misterioso de los otros hombres en su alteridad. Y hasta qué punto nosotros, llevados de la fuerza del pensamiento asimilatorio griego-metafísico, hemos convertido siempre a los otros en una función, más o menos positiva o negativa, de nosotros mismos, de nuestros problemas de identidad, de nuestro acceso al yo: y esto incluso en las teorías de la intersubjetividad. Y qué poco hemos comprendido lo lejano y extraño - que nada ni nadie puede eliminar- del Otro, la orden aparece en su rostro de dejarle seguir siendo el Otro. (Metz \& Wiesel, 1996, pp. 43-44)

La solidaridad manteniendo su unidad con las categorías de recuerdo y narración se presenta como la realización del compromiso práctico del cristiano. La decisión efectiva por el seguimiento de Cristo eleva al creyente en la experiencia sublime de la caridad, sobre todo, hacia aquellos que son víctimas.

\section{b. Solidaridad Universal}

Elemento significativo en la praxis cristiana, es precisamente, su carácter de universalidad, que brota del apoteósico y singular acontecimiento de la encarnación. A partir de este hecho sin precedentes, la categoría teológica de solidaridad adquiere unas dimensiones inimaginables dentro de un horizonte universal. Vivimos una época de sensibilidad por lo global, por la unificación de los espacios y la información a nivel mundial. Los vínculos de relaciones se mueven con una rapidez impresionante gracias a las distancias acortadas por los medios de comunicación cada vez más avanzados y efectivos. La Ilustración ha dejado en la conciencia humana una sensibilidad atenta a cualquier perturbación del orden moral y ético que perjudique la convivencia y el progreso de la raza humana. En medio de esta realidad se podría hablar de una solidaridad globalizada, sin embargo, esta realidad global no agota el significado profundo de la solidaridad cristiana.

La solidaridad cristiana es una categoría teológica que tiene que ver con el seguimiento de Cristo, que ha optado por la causa del hombre, sin encasillarse en niveles políticos, sociales, económicos. Su preocupación es el ser humano y sobre todo, el sufriente. El cristianismo siguiendo a Cristo también hace una opción preferencial por el ser humano, para que éste logre ser sujeto de la solidaridad universal de Dios.

La Iglesia es la llamada a ser la impulsadora de los proyectos de solidaridad universal comprometiéndose de manera efectiva con los problemas que conlleva la opción preferencial por las víctimas. Este camino coloca un derrotero seguro en el diálogo inter religioso y la participación de la Iglesia en ambientes, que por la privatización de la teología se han descuidado, como por ejemplo: la historia, las culturas, las ciencias, la economía y la política.

La conciencia eclesial, como la abanderada en 
la universalidad de la caridad que protege a los débiles, es el cometido de una teología política aplicada en la praxis cristiana y por tanto revolucionaria en medio de las condiciones injustas y opresoras de los sistemas dominantes de la historia contemporánea. Para la Iglesia el compromiso con la solidaridad representa un reto, pero a la vez refleja su función más originaria.

\section{Conclusiones}

La obra teológica desarrollada por Metz ha sido el resultado de la preocupación del teólogo por la legitimación del cristianismo en las condiciones críticas que ha dejado, en el mundo y la historia, un incontrolable movimiento de secularización, emancipación e Ilustración, propiciado por la racionalidad y la subjetividad de la Edad Moderna. Esta preocupación es expresada constantemente en las obras de Metz (1968) con la siguiente afirmación: "La teología ha reducido el núcleo central del mensaje al ámbito privado y la práctica de la fe a una decisión de espaldas al mundo". (p. 387). Metz es exponente de la teología fundamental, en cuanto toca las fronteras de la relación entre teología e historia, teoría y praxis, teología y religión y las presenta reconciliadas sistemáticamente en el escenario de la historia y el mundo formado por seres humanos, capaces de ser sujetos de la praxis teológica transformadora de la realidad infortunada de los sufrientes. Las experiencias de confrontación con su contexto histórico y la formación filosófica idealista y trascendental han hecho de Metz un exponente de la teología fundamental y el gestor de la llamada nueva teología política.

Es oportuno observar que en el trasfondo de la propuesta de Metz se ha venido elaborando una cristología que ilumina la consolidación de un nuevo sujeto creyente, que será el responsable de llevar a cabo este proyecto de teología política como teología fundamental práctica. $\mathrm{Al}$ respecto, en una publicación reciente el teólogo chileno Juan Pablo Espinosa Arce, afirma: "Jesucristo es pues el paradigma de este nuevo sujeto, del que es constituido en el sujeto por excelencia de la nueva historia, de la historia escatológica. Y esta esperanza es una de la que se hace memoria y narración, categorías políticas y centrales de la teología de Metz". (Espinosa Arce, 2016, p. 142). Por tanto, las categorías de la teología política solo pueden ser apropiadas por un sujeto que en la persona de Jesucristo encuentra el paradigma de hombre y sociedad, un sujeto reconciliado con la historia y en apertura a la construcción de un futuro posible en el seguimiento de Cristo.

En la propuesta teológica de Metz sobresale la experiencia de cuestionamiento permanente sobre la forma de abordar los problemas actuales y que animan el trabajo por la consecución de una actitud teológica madura a través de tres características que deben acompañar el trabajo y la vida del teólogo: la crítica, el diálogo y la praxis. En la presentación de estas características quisiera recoger, a modo de conclusión, la llamada actual de la teología fundamental en la búsqueda de un horizonte de profundización de la fe y el anonadado esfuerzo por dar razones de la esperanza en medio de los profundos cuestionamientos de la humanidad.

\section{Actitud teológica crítica}

La actitud crítica se entiende como la capacidad de mirar más allá de la apariencia de los fenómenos, de los acontecimientos, para dar paso a la verdad y el logos de la teología. La crítica es el esfuerzo por descubrir el fundamento de la realidad en la cual se desarrolla la libre comunicación de Dios y la repuesta vital del creyente. En medio de las actuales condiciones de un mundo fragmentado y distorsionado se hace necesaria la exaltación de los vínculos que superen las fracturas ocasionadas por el triunfo de la razón ilustra- 
da y el ocultamiento de la religión en la esfera de un discurso privado y burgués.

La crítica y la autocrítica ayudan a la teología en el esfuerzo por alejarse de los peligros de la privatización y el divorcio de la dimensión histórico-social. La teología fundamental con ayuda de la crítica puede alcanzar sus objetivos porque ella encuentra en la relación entre fides et ratio el lugar privilegiado de su competencia como ciencia teológica, y busca desarrollar un discurso evocador que permite acoger la fe cristiana con toda la credibilidad y operatividad. La teología fundamental se preocupa por la situación concreta del ser humano a quién Dios comunica su Palabra cercana y definitiva, dentro de las dimensiones sociales e históricas.

\section{Actitud teológica dialogal-narrativa}

Una segunda actitud teológica es el diálogo que implica, además de saber expresar los contenidos propios, conocer y escuchar las voces de quienes se excluyen o son excluidos. Para fortalecer esta dimensión del quehacer teológico debemos aprender a escuchar las voces de la historia y el desarrollo del progreso humano, para contextualizar y así pronunciar el discurso sobre Dios, por medio de un lenguaje evocador que permita la escucha de la Palabra reveladora de Dios, siempre viva y actual en su Hijo muerto y resucitado.

No podemos hablar de Dios en las condiciones del mundo actual si no conocemos con certeza el contenido de lo que anunciamos y si no tenemos en cuenta al hombre en el conjunto de su experiencia vital. La teología debe ser la voz y debe hablar a aquellos que no pueden expresar su clamor o sus preguntas sobre Dios. El carácter dialogal de la teología debe estar lejano de todo discurso privado o burgués, que no habla ni responde a las inquietudes profundas del ser humano.

Elemento importante en esta actitud dialogal, es el coraje que debe poseer el teólogo para abordar los contenidos de ciencias auxiliares, como, por ejemplo: la sociología, la política, la antropología y la psicología, si quiere que el discurso teológico esté a la altura del juego lingüístico que ha envuelto la historia de la humanidad moderna y contemporánea, y del cual se ha querido sacar el discurso metafísico y religioso. La pluralidad de formas y estructuras cambiantes en las cuales se va envolviendo el ser humano dejan de lado las dimensiones de la memoria y la trascendencia, para vivir en el eterno presente y el materialismo vertiginoso que lo lanzan al profundo abismo del sin sentido y la desesperanza.

Con esta apertura al diálogo la teología puede ir adquiriendo un lenguaje evocador que dirija la experiencia humana hacia la trascendencia y le comprometa en la consolidación de la praxis trasformadora en el contexto histórico presente. La categoría de la narración nos ofrece un camino pastoral seguro que pasa por la evocación y las narraciones vitales, las cuales dan paso a la experiencia del discipulado, sobre todo, como actualización de la peligrosa memoria de Jesucristo muerto y resucitado, que es trasmitida por la Iglesia y aceptada en el mundo con un poder subversivo y trasformador.

\section{Actitud teológica práctica}

La revaloración de la dimensión práctica de la fe es el esfuerzo permanente de la nueva reflexión teológica propuesta por Metz. Es por medio de la crítica y de la praxis como la Iglesia puede rechazar el peligroso camino de la privatización del discurso teológico y de la vivencia del cristianismo lejano de la historia y de la memoria de quienes claman justicia. La praxis debe ser entendida desde la amplitud del cometido de la experiencia creyente del cristiano, donde la razón y la fe no son opuestas sino complementarias.

La ratificación de la dimensión práctica del cristianismo está lejos de reducir la fe a un conjunto 
axiológico, ético o exclusivamente moralista; esta praxis es un reclamo de sentido de la historia y de la esperanza escatológica, donde la comunicación de Dios y la respuesta del hombre se armonizan en la construcción de una sociedad más justa y libre.

En el contexto de la época actual, donde se vive una transición de la modernidad a una posmodernidad existe mayor sensibilidad por las voces del testimonio, el afecto y el sentido. Esta condición puede ser un camino abierto para el cristianismo y la teología, que posee un mensaje de vida y sentido, marcado no sólo por un discurso, sino por la experiencia existencial de Jesucristo que le da sentido al drama y a los cuestionamientos más profundos del ser humano. Es la memoria de Jesucristo encarnado, sufriente, muerto y resucitado el testimonio de la experiencia fundamental que debemos transmitir en medio de la historia actual.

Hoy no se puede hacer teología alejándose de la historia, el lenguaje y la cultura del hombre posmoderno. Hablar de Dios en el mundo contemporáneo pasa de la demostración a la mostración del misterio que da sentido y fundamento a la historia personal y social. La praxis debe ser realizada por un sujeto humano que considera en la estructura profunda de su ser una interpelación espiritual a ser seguidor de la verdad y a luchar contra el olvido del sufrimiento de las víctimas, que ha dejado el desarrollo de la secularización negativa en virtud del progreso.

El teólogo debe asumir un compromiso serio con la reflexión teológica que lo conduzca a la madurez de un pensamiento crítico, narrativo y práctico, siendo fiel a la Palabra de Dios comunicada en la historia y en la persona humana. La teología, como discurso sobre Dios, deberá ser comunicada de tal forma que alcance su fuerza como Palabra de significación y liberación personal y social.

\section{Referencias}

Metz, J. B. (1979). La fe, en la historia y la sociedad. (M. O. Bravo, Trad.) Madrid, Madrid, España: Cristiandad.

Metz, J. B. (2002). Dios y tiempo. Madrid, Madrid, España: Trotta.

Metz, J. B. (1973). Breve apología de la narración. Concilium (84), 222-238.

Metz, J. B., \& Wiesel , E. (1996). Esperar a pesar de todo. (C. Gauger, Trad.) Madrid, Madrid, España: Trotta.

Metz, J. B. (1968). El problema de una teología política. Concilium (36), 385-403.

Metz, J. B. (2007). Memoria Passionis. Una evocación provocadora en una sociedad pluralista. (J. M. Gotor, Trad.) Santander, Santander, España: Sal Terrae.

Metz, J. B. (1970). Teología del mundo. (C. R. Garrido, Trad.) Salamanca, España: Sígueme.

Espinosa Arce, J. P. (2016). Johann Baptist Metz y la teología cristiana después de Auschwitz. Cuestiones Teológicas , 43 (99), 133-147.

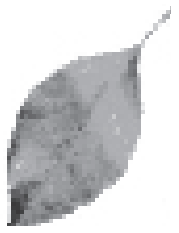

